\title{
Letters
}

Website: bmj.com

Email: letters@bmj.com

\section{Information needs of patients with cancer}

\section{Patients are frightened and their} information needs fluctuate

EDITOR-I read the paper by Leydon et al on the information needs of patients with cancer ${ }^{1}$ and comment both as a researcher with a particular interest in the provision of patient information and as a patient who received a diagnosis of cancer last year.

In addition to faith, hope, and charity, the patients' narratives illustrate the part fear plays in preventing patients with cancer from seeking information. The quotations in the paper echo many of my own fears, which at times prevented me from seeking information: one is frightened of finding out something bad (box 2, quote 4), one is frightened of jumping to the wrong conclusions through ignorance (box 1, quote 3) or lack of specific information about one's own condition (box 2, quote 2 and quote 6), and one is frightened of being labelled a "clever dick" (box 1, quote 4). It is important to differentiate between patients who do not seek further information about their condition because they are frightened of the potential content and those who do not seek further information because they are reluctant to ask for more details, even when they do want them

\section{Advice to authors}

We prefer to receive all responses electronically, sent either directly to our website or to the editorial office as email or on a disk. Processing your letter will be delayed unless it arrives in an electronic form.

We are now posting all direct submissions to our website within 24 hours of receipt and our intention is to post all other electronic submissions there as well. All responses will be eligible for publication in the paper journal.

Responses should be under 400 words and relate to articles published in the preceding month. They should include $\leqslant 5$ references, in the Vancouver style, including one to the BMJ article to which they relate. We welcome illustrations.

Please supply each author's current appointment and full address, and a phone or fax number or email address for the corresponding author. We ask authors to declare any competing interest. Please send a stamped addressed envelope if you would like to know whether your letter has been accepted or rejected.

Letters will be edited and may be shortened.

bmj.com

letters@bmj.com (box 3, quote 2). The challenge for health professionals is to distinguish when patients want more detailed information, and the onus is on them to provide it. This will help patients to extract relevant information from other sources.

The narratives also illustrate the fluctuating information requirements of individual patients during the course of their illness (box 1 , quote 4 ; box 2 , quote 2 and quote 3 ), and the authors justifiably recommend further research taking a longitudinal approach to explore the changing nature of patients' orientations. Again, this mirrors my own experience. I wanted as much information as possible, but nevertheless I was terrified of being told the results of my biopsy at one visit to the clinic as I was mentally unprepared (having expected to be told the following week). There was also an internet site that I was unwilling to access on one occasion but that I readily opened a few weeks later.

In developing recommendations, the government's cancer information strategy should attend to these variations over time within individuals, in addition to the variations between patients in their desire for information.

Anne Fleissig research psychologist

Cancer Research Campaign Psychosocial Oncology Group, Royal Free and University College London Medical School, London W1P 7PL

a.fleissig@ucl.ac.uk

1 Leydon GM, Moynihan C, Boulton M, Mossman J, Boudioni M, McPherson K. Cancer patients' information need and information seeking behaviour: in depth interview study. $B M J$ 2000;320:909-13. (1 April.)

\section{Similar study had similar findings}

EDITOR-In December 1998 we undertook a similar qualitative study to the one reported by Leydon et al, ${ }^{1}$ using in depth interviews with 24 patients who had been given a diagnosis of cancer in the preceding 12 months; we achieved remarkably similar results.

All of the patients interviewed stated that they had experienced difficulty in retaining information given to them at the consultation when the diagnosis was given. Patients in our study also felt reluctant to ask questions if doctors and nurses appeared "too busy," afraid of making further demands on their time.

It was common for patients or a close relative to contact their general practitioner 24-48 hours after receiving the diagnosis in an attempt to gain further information.
Patients expected their general practitioner to be aware of their diagnosis, which was often not the case.

We now have a system in place that ensures that consultants can request that a hospital Macmillan nurse be present when the diagnosis is given. A comfortable private area is provided after consultation, and the Macmillan nurse can accompany the patient. The Macmillan nurse provides an outline of the patient's understanding and immediate management plan to the general practitioner by telephone on the same day or within 24 hours.

John McKenzie integrated care pathway coordinator (Moray)

Grampian University Hospitals, Clinical

Effectiveness Department, Elgin IV31 6RN

johnmckenzie@bigfoot.com

1 Leydon GM, Moynihan C, Boulton M, Mossman J, Boudioni M, McPherson K. Cancer patients' information needs and information seeking behaviour: in depth interview study. BMJ 2000;320:909-13. (1 April)

\section{Patients' perspectives may vary}

EDITOR-As breast cancer survivors and consumer advocates, we know only too well the trauma associated with a diagnosis of cancer. With this background we find the study by Leydon et al disturbing and disappointing on many counts.

Although it is true that not all patients wish to know the nature, cause, and treatment options for their disease, there is evidence showing that virtually all patients have a deep seated need for specific information. ${ }^{2.3}$

The recently released Australian guidelines for psychosocial clinical practice summarise relevant research as follows.

"Women with cancer repeatedly report a desire to be well informed. Research also indicated that up to $60 \%$ prefer key information to come from a hospital doctor. Effective communication, however, involves more than the provision of information; it requires a process of individually tailored explanation, problem-solving and acknowledgment of the woman's feelings."

Why is it, then, that studies such as the one by Leydon et al continue to emphasise those patients who show little explicit need for information? Why can we not accept that there are many different reactions-from people who wish to know everything to those who wish to know almost nothing?

One of the disturbing factors about the study is its consistent portrayal of the patient as the necessary initiator of the information seeking process. Implicit throughout is the assumption that unless the patient actively seeks further information, he or she must therefore not desire any added information. 
Silence in this case does not automatically equate to satisfaction with information provision but possibly with resignation to the limitations of the system and lack of knowledge of exactly what to ask.

Similarly, if "confusion" is one reason for avoiding information this is possibly a reflection on the quality of that information and the way it has been presented, rather than a patient's desire to know and understand. To parade this as "avoidance" is merely to show a complete lack of understanding of patients' needs. This same argument can be applied to many other strategies listed by the study. Such an approach interprets the interaction between doctor and patient purely from the doctor's point of view.

With the combined experiences of consumers and evidence now available, it is time to move on and together work out how best to provide information-not to continue to argue about the need.

\section{Sue Lockwood chair}

Rosetta Manaszewicz steering committee

Breast Cancer Action Group, PO Box 281, Fairfield,

Victoria 3078, Australia

rosetta@netspace.net.au

1 Leydon GM, Moynihan C, Boulton M, Mossman J, Boudioni M, McPherson K. Cancer patients' information need and information seeking behaviour: in depth interview and information seeking behaviour:

2 Butow PN, MacLean M, Dunn SM. The dynamics of change: cancer patients' preferences for information involvement and support. Ann Oncology 1997;8:857-63.

Luker K, Beaver K, Leinster S, Owens R, Degner L, Sloan J The information needs of women newly diagnosed with breast cancer.J Adv Nursing 1995;22:134-41

4 National Health and Medical Research Council National Breast Cancer Centre. Psychosocial clinical practice guidelines: providing information, support and counseling for women with breast cancer. Canberra: Commonwealth of Australia, 2000.

\section{Authors' reply}

EDITOR-Our article on patients' information seeking and information needs has provoked a broad range of reactions. Fleissig and McKenzie reiterate some of the issues raised in our paper. Fleissig summarises many of the complexities that we attempted to convey; in particular, the way information requirements fluctuate during the course of patients' experience of cancer in accordance with individuals' orientations towards faith, hope, and charity.

Lockwood and Manaszewicz point out that it is well established that patients require as much information as possible, but some patients do not feel they get enough information, and some prefer minimal information. Our study examined the strategies adopted by patients for seeking and avoiding information. We show that patients' seeking strategies fluctuate, sometimes by the minute. It is imperative that we view patients' needs as fluid, individual, and unexpected, and, even if counterintuitive, these needs should be dominant.

We agree that women have been the focus of most research regarding information needs. Our study begins to illuminate important differences between the sexes regarding information needs and seeking behaviours, "silence" being a case in point. We have interpreted silence as "avoidance" (and other strategies) only through careful contextual, theoretically informed analysis. We have also, however, reminded readers that external constraints may act as silencers in the cancer context. A desire for no information at points in the experience of the illness can reflect a positive and rational choice. Such a choice can be indicative of individual autonomy and is one of many possible decisions to be made in the face of adversity.

We reject the assertion that our approach interprets the interaction between doctor and patient purely from the doctor's point of view. We have illuminated the need for all health professionals to be sensitive to ambiguity. Only when we begin to unpack the unequivocal ambiguity surrounding patients' reasons for non-use of information can we accurately assess whether there is unmet need. We would not subscribe to normative, blanket policies regarding the provision of information. We should instead attempt to understand the complexities of patients' information seeking and non-seeking, by properly analysing the diverse experiences of consumers. It will then be time to move on and establish how best to share in the complex process of information exchange. Until then, we believe that patients' information needs and health seeking behaviours certainly merit further attention.

Geraldine Leydon research fellow in cancer Cancer and Public Health Unit, Department of Epidemiology and Population Health, London School of Hygiene and Tropical Medicine, London WC1E 7HT

g.leydon@lshtm.ac.uk

Clare Moynihan medical sociologist

Institute of Cancer Research and the Royal Marsden NHS Trust, Sutton SM2 5PT

Mary Boulton professor of sociology

School of Social Sciences and Law, Oxford Brookes University, Oxford OX3 0BP

Alison Jones consultant in oncology

Royal Free Hospital School of Medicine, Royal Free Hospital, London NW3 2QG

Jean Mossman chief executive

Markella Boudioni research officer

CancerBACUP, London EC2A 3JR

Klim McPherson professor of public health

epidemiology

Cancer and Public Health Unit, Department of

Epidemiology and Population Health, London

School of Hygiene and Tropical Medicine, London WC1E 7HT

\section{Breaking down barriers for refugee doctors}

\section{Doctors can qualify in the United Kingdom}

EDITOR-Adams and Borman were right to draw attention to the need for the medical profession to help refugee doctors. ${ }^{1}$ The United Examining Board does provide a method for these doctors to qualify in the United Kingdom and to be registered with the General Medical Council. It replaced three examinations - the conjoint examination run by the Royal Colleges of Physicians of London and Surgeons of England, the Scottish triple examinations run by the three Scottish royal colleges, and the licence of the
Society of Apothecaries of London. Before candidates can sit these examinations they have to undergo a period of training and assessment in a British university.

Adams and Borman say that a mechanism needs to be established to identify refugee doctors with a good chance of re-establishing their medical careers. The United Examining Board provides this identification as it has established a preliminary examination that is used by the universities to decide who might most benefit by clinical attachment in a university hospital prior to taking the qualifying examination.

This is the only examining board route for refugee medical students who have yet to qualify as doctors. The United Examining Board has certain medical schools that organise the necessary clinical training-for example, St George's Hospital Medical School in London. For more information please contact the board's office at the Society of Apothecaries.

Roger Parker master apothecary

Worshipful Society of Apothecaries of London, London EC4V 6EJ

1 Adams K, Borman E. Helping refugee doctors. BMJ 2000;320:887-8. (1 April.)

\section{Secure statutory funding is needed}

EDITOR-As Adams and Borman pointed out in their editorial, settled refugee doctors face many difficulties. ${ }^{1}$ We have seen more than 200 during the three years that we have been working with them. Their cross cultural and linguistic skills could be especially valuable in a multicultural society. We have observed both a sense of humiliation at their reliance on benefits and a fierce determination to re-enter their profession. Recent policy changes further undermine their positionfor example, supermarket vouchers cannot fund access to medical libraries. ${ }^{2}$ Our experience has identified some problems and possible solutions that may be of interest to areas receiving refugee professionals.

- No single body takes overall responsibility; a London-wide steering group including the voluntary sector, higher education, postgraduate medical education, and local authorities has proved invaluable

- Self directed learning groups for medical education and support have been very popular. The first, of three, London clubs was in east London facilitated by one of us, a general practitioner (SC). There is continuing unmet demand for these clubs

- A clinical and communication skills course has taught 20 doctors over 15 afternoons at a cost, excluding teaching staff time, of $£ 10000$. Half the students are now working as doctors. In contrast it takes $£ 200000-£ 250000$ to train a doctor from undergraduate entry

- One day conferences have brought together isolated refugee doctors and supportive agencies

- A refugee doctors' guide has proved an invaluable information resource to refugee doctors and agencies assisting them.

Notwithstanding our achievements with short term insecure charitable funding, this 
work needs secure statutory funding to make it sustainable and to ensure that the demand is met. Associate membership of the BMA for refugee doctors, at a price commensurate with their income, would improve their self esteem and provide a reliable non-governmental register. Many doctors are willing to donate time to help their professional colleagues. As well as funding for study club facilitators, career advisers, and mentors, an infrastructure is needed to recruit, support, and organise volunteers. The work is in line with the government's aim of "joined up government" and is both humane and cost effective. (Volunteers please contact SC or EF.)

Sheila Cheeroth clinical lecture

s.a.cheeroth@mds.qmw.ac.uk

Martin Underwood senior lecturer

Yvonne Carter professor

Department of General Practice and Primary Care, St Bartholomew's and the Royal London School of Medicine and Dentistry, Queen Mary and Westfield College, London E1 4NS

Edie Friedman director

Jewish Council for Racial Equality, West London Synagogue of British Jews, London W1H 5AU

jcore@btinternet.com

1 Adams K, Borman E. Helping refugee doctors. $B M$ J 2000;320:887-8. (1 April.)

2 Connelly J, Schweiger M. The health risks of the UK's new asylum act. $B M J$ 200;321:5-6. (1 July.)

3 Jewish Council for Racial Equality. A guide for refugee doctors. 2nd ed. London: JCORE, 1999. (Available from the Jewish Council for Racial Equality.)

\section{National service framework for coronary heart disease}

\section{Ambiguities need to be clarified}

Editor-One of the priorities in the national service framework for coronary heart disease summarised by Mayor ${ }^{1}$ was "improved use of effective medicines after heart attack-especially aspirin, $\beta$ blockers, and statins-so that $80-90 \%$ of people discharged from hospital after a heart attack will be prescribed these drugs." This is the recommendation in the executive summary, which taken at face value implies that all three drugs should be prescribed before a patient leaves hospital. In contrast, the recommendation in the main document is that aspirin and $\beta$ blocker treatment should be started in hospital and statin treatment left for "continuing care."

Statin treatment was not started at the time of infarction in any of the large secondary prevention studies. The shortest times from infarction to inclusion were six months in the Scandinavian simvastatin survival study (4S), ${ }^{2}$ and three months in the cholesterol and recurrent events (CARE) study ${ }^{3}$ and the long term intervention with pravastatin in ischaemic disease (LIPID) study. Thus the common practice of starting treatment before discharge is not strictly evidence based and statin treatment may be harmful immediately after myocardial infarction. Starting treatment before discharge, however, ensures that the drug is prescribed and simplifies audit.
A further recommendation in the main document is "give statins to lower serum cholesterol concentrations either to less than $5 \mathrm{mmol} / \mathrm{l}$ (low density lipoprotein cholesterol below $3 \mathrm{mmol} / \mathrm{l}$ ) or by $30 \%$ (whichever is greater)." I find this ambiguous because a percentage change cannot be compared to a concentration, but I presume that the intention is to exclude from treatment those with a total cholesterol concentration under $5 \mathrm{mmol} / \mathrm{l}$ on admission. An audit of my own patients with myocardial infarction showed that statin treatment was not appropriate in 22\% for this reason.

The main document states that patients with acute myocardial infarction should usually receive the recommended interventions unless contraindicated. Surely all patients without intolerance or contradindications should receive aspirin and $\beta$ blockers. Similarly, all patients with a total cholesterol concentration greater than or equal to $5 \mathrm{mmol} / \mathrm{l}$ should be treated with a statin, but they may number less than $80 \%$ of the total. Whether the $80-90 \%$ standard above applies to all patients or to those without contraindications is not clear.

These ambiguities need to be clarified or the results of comparative audit will be meaningless. The criteria for audit should be as rigorous as those for clinical trials.

Roger Lloyd-Mostyn consultant physicia King's Mill Centre, Sutton-in-Ashfield, Nottinghamshire NG17 4JL

Competing interests: Dr Lloyd-Mostyn has been reimbursed for attending conferences and speaking at meetings by companies that manufacture lipid lowering drugs.

1. Mayor S. Heart disease framework aims to cut deaths in England. BMJ 2000;320:665. (11 March)

2 Scandinavian Simvastatin Survival Group. Baseline serum 2 Scandinavian Simvastatin Survival Group. Baseline serum
cholesterol and treatment effect in the Scandinavian cholesterol and treatment effect in the Scandinavian
simvastatin survival study (4S). Lancet 1995;345:1274-5. simvastatin survival study (4S). Lancet 1995;345:1274-5.
Sacks FM, Pfeffer MA, Moye LA, Rouleau JL, Rutherford JD, Cole TG, et al. The effect of pravastatin on coronary events after myocardial infarction in patients with average cholesterol levels. N Engl J Med 1996;335:1001-9.

4 Long Term Intervention with Pravastatin in Ischaemic Disease (LIPID) Group. Prevention of cardiovascula events and death with pravastatin in patients with coronary heart disease and a broad range of initial cholesterol levels. N Engl J Med 1998;339:1349-57.

\section{Target of lowering cholesterol by $30 \%$} needs to be justified

EDITOR-The target cholesterol concentration of the national service framework for coronary heart disease seems to be problematic, ${ }^{1}$ which has important consequences for primary care. Most clinicians agree about the value of evidence based guidelines in preventing coronary heart disease and the need for clarity. But the recommendation to reduce cholesterol concentration by $30 \%$ is not based on evidence, and at worst seems to be arbitrary, thus weakening the document.

The issue of using cholesterol target concentrations or percentage reductions has been discussed, ${ }^{2}$ and the consensus among recent guidelines is to aim for a target cholesterol concentration of less than $5.0 \mathrm{mmol} / \mathrm{I}^{3}{ }^{3}$ The original guidance on the use of statins from the Standing Medical Advisory Committee in 1997 suggested a reduction in cholesterol concentration of $20-25 \%$ in line with the outcome trials, and the developers of the new Sheffield table ${ }^{5}$ suggest $25 \%$ (L E Ramsay, personal communication).

I am concerned that the national service framework's target of 30\% will become a national audit standard that will be difficult to achieve, with adverse consequences for primary care. It would penalise good management, result in more visits and tests, and demoralise staff and patients. To achieve this target higher doses of statins might be used beyond the trial doses $(40 \mathrm{mg})$, or most patients might be given atorvastatin (which does not have yet any trial evidence). Side effects may increase and the ratio of risk to benefit may shift. This has major implications as statins become more widely used in large populations. In the interests of fostering healthy debate, it would be helpful for the national service framework to justify the $30 \%$ figure.

Paul Cracknell general practitioner

Killamarsh Medical Practice, Sheffield S21 4DJ paul.cracknell@virgin.net

Competing interests: None declared.

1 Department of Health. National service framework for coronary heart disease. London: $\mathrm{DoH}, 2000$.

2 Rosengren A. Cholesterol: how low is low enough? BMJ 1998:317:425-6.

3 Wood D, Durrington P, Poulter N, McInnes G, Rees A, Wray R on behalf of the British Cardiac Society, British Hyperlipidaemia Association, British Hypertension Society and endorsed by the British Diabetic association. Joint British recommendations on prevention of coronary heart disease in clinical practice. Heart 1998;80(suppl 2):S1-29.

4 Scottish Intercollegiate Guidelines Network. Lipids and the primary prevention of coromary heart disease. Edinburgh: SIGN, 1999. (Clinical guideline No 40.)

5 Wallis EJ, Ramsay LE, Ul Haq U, Ghahramani P, Jackson PR, Rowland-Yeo K, et al. Coronary and cardiovascular risk estimation for primary prevention: validation of a new Sheffield table in the 1995 Scottish health survey population. BMJ 2000;320:671-6. (11 March.)

\section{Many operators and facilities will not} meet standards set out in framework

EDITOR-Mayor's news item reported the publication of the national framework for coronary heart disease for England. Section 2 of the framework focuses on improving the quality of care offered to patients with coronary heart disease. ${ }^{2}$ It publishes standards that operators and facilities for interventional cardiological procedures are expected to achieve. Some of these standards address the annual number of cardiac catheterisations, coronary angioplasties, and coronary artery bypass operations that operators and facilities must achieve.

We used the hospital episode system database for the West Midlands for the most recent year available (1 April 1996 to 31 March 1997) for a study that we carried out. We calculated the proportion of facilities and consultant firms in the West Midlands providing services that complied with these new standards, and the proportion of patients treated by these facilities and consultant firms.

Data on the hospital episode system record the consultant firm, not the person doing the procedure, so we used the consultant firm as a proxy for the individual operator. The effect of this would be to overestimate the proportion of procedures done by "above threshold" operators. To reduce 
Interventional cardiological procedures in 1996-7 with standards set out in national service framework for coronary heart disease. Values are numbers (percentages) unless stated otherwise

\begin{tabular}{lccc} 
& $\begin{array}{c}\text { Cardiac } \\
\text { catheterisation }\end{array}$ & $\begin{array}{c}\text { Coronary } \\
\text { angioplasty }\end{array}$ & $\begin{array}{c}\text { Coronary artery } \\
\text { bypass grafting }\end{array}$ \\
\hline NSF standard for minimum No of procedures per facility & 500 & 200 & 400 \\
\hline Institutions reaching threshold & $5 / 15(33)$ & $3 / 8(38)$ & $3 / 3(100)$ \\
\hline NSF standard for minimum No of procedures per operator & 100 & 75 & 50 \\
\hline Consultant firms reaching threshold & $33 / 100(33)$ & $7 / 48(15)$ & $11 / 14(79)$ \\
\hline Total No of procedures during 12 month period & 9037 & 1521 & 2308 \\
\hline Procedures in facility below threshold: & & & \\
\hline By consultant firm below threshold & $322(3.5)$ & $290(19.1)$ & 0 \\
\hline By consultant firm above threshold & $1458(16.1)$ & 0 & 0 \\
\hline Procedures in facility above threshold: & & & \\
\hline By consultant firm below threshold & $820(9.1)$ & $128(8.4)$ & $32(1.4)$ \\
\hline By consultant firm above threshold & $6437(71.2)$ & $1103(72.5)$ & $2276(98.4)$ \\
\hline
\end{tabular}

NSF=national service framework. Denominators vary because of missing data

bias from coding errors we excluded consultants and trusts that undertook only one procedure during 1996-7 unless they had undertaken that procedure for three consecutive years.

The table shows the results. While $98 \%$ of patients had their coronary artery bypass grafting done in an above threshold facility by an above threshold consultant firm, the proportions for coronary angioplasty and cardiac catheterisation were only $73 \%$ and $71 \%$ respectively. We looked in more detail at cardiac catheterisations: of the 1780 patients treated in a below threshold facility, 1458 were operated on by an above threshold consultant firm. To comply with the national service framework's standards 10 facilities in the West Midlands would have to stop doing cardiac catheterisations (despite most patients being treated by cardiologists with an adequate caseload) or cases would have to be redistributed between hospitals.

These findings show that unless cardiac catheterisation and coronary angioplasty practices have changed since 1996-7, many operators and facilities will not meet the standards set out in the national service framework. We are aware that over the past few years many more patients have undergone coronary stenting and angioplasty, and the proportion of patients treated by individual cardiologists is therefore likely to have improved. This, however, needs to be established.

Kate Jolly lecturer in public health and epidemiology C.B.Jolly@bham.ac.uk

Andrew Rouse senior lecturer in public health and epidemiology

University of Birmingham, Birmingham B15 2TT

Greg Y H Lip reader in medicine

University Department of Medicine, City Hospital, Birmingham B18 7QH

Competing interests: None declared.

1 Mayor S. Heart disease framework aims to cut deaths in England. BMJ 2000;320:665. (11 March.)

2 Department of Health. National service framework for coronary heart disease. London: DoH, 2000.

\section{Brain stem death}

Patients' interests should predominate

EDITOR-Although Inwald et al describe how consensus and sensitivity have helped a family and staff concerned to live through a difficult and sad time, I take issue with two points they raise.

I agree with their statement that families should not be pressurised into consenting to withdrawal of care and should not be asked to become accessories to murder. It is an unfair burden to put on any family member to share responsibility in a decision to withdraw treatment, and there is no need for it. Medical treatment or the cessation of it should be guided by evidence of its effectiveness and society's acceptance of its desirability in general (as society bears the cost). Only the patient has the right to deny himself a universally accepted treatment but not the right to demand a treatment that cannot be offered to others as well.

In the case described by Inwald et al, brain stem death is a medical diagnosis, hence cessation of artificial ventilation of a dead patient is a medical decision. Although families must have the right to be guided through the decision making process, it remains ultimately medical.

"The aim of intensive care should be to treat the family, not just the patient." I find this statement alarming, leading us straight into a bottomless pit. Which family interests are we supposed to treat? Do we always know about hidden agendas in families? Can we allow this luxury to all families? What do we say to families whose relatives we cannot treat because of a shortage of beds (a common problem) when at the same time allowing other families to exercise a choice society is not able to fund? Reality can be very sad and hard to accept, but it must be seen to be fair. For us doctors the interests of our patients-actual patients and potential ones-have to overrule all other interests, and families should not be treated in intensive care but helped to accept the inevitable.

Ruth Deroy senior registrar in anaesthesia Norfolk and Norwich Health Care NHS Trust, Norwich NR1 3SR

hilgera@ipsh-tr.anglox.nhs.uk

1 Inwald D, Jakobovits I, Petros A, Fisher M, Raper RF. Brain stem death: managing care when accepted medical guidelines and religious beliefs are in conflict. BMJ 2000;320:1266-8. (6 May.)

\section{Healthcare workers have difficulty} accepting current management

EDitor-The ethical debate and subsequent commentary on the management of care in a young Jewish girl who was brainstem dead has parallels close to home for anaesthetists. ${ }^{1}$ Fisher and Raper are worried that if we accommodate the requirements of any particular group then we should accommodate the requirements of all groups, however unreasonable.

The suggestions of one particular group are illustrated in a recent editorial in Anaesthesia by Young and Matta, ${ }^{2}$ who conclude that sedation and analgesia should be given with muscle relaxation for organ donation since brain stem death tests are arbitrary. In other words, some members of the anaesthetics community are not absolutely convinced of the reliance of brain stem death tests to equate with the lack of capacity for suffering. The acceptability of organ donation rests on the assumption that the donor is irrevocably and absolutely dead rather than just in the process of dying. In their final paragraph, however, Young and Matta again suggest that we should provide general anaesthesia for organ donation to prevent the haemodynamic responses to surgery that are distressing for operating theatre personnel and because it is imperative that public confidence in the transplant programme is maintained.

In conclusion, it is not only members of orthodox (or unorthodox) religious groups who have problems accepting the current hospital management of brain stem dead people-healthcare workers (including doctors) who participate in the transplantation of their organs are also affected.

Daniel Dalgleish specialist registrar anaesthesia Jersey General Hospital, St Helier, Jersey JE2 3QS djdalgleish@hotmail.com

1 Inwald D, Jakobovits I, Petros A, Fisher M, Raper RF. Brain stem death: managing care when accepted medical guidelines and religious beliefs are in conflict. BMJ 2000;320:1266-7. (6 May.)

2 Young PJ, Matta BF. Anaesthesia for organ donation in the brainstem dead-why bother? Anaesthesia 2000;55:105-6.

\section{Doctors are unsympathetic to colleagues who are psychologically vulnerable}

Editor-Clark's article on why people become doctors is of interest not only for her understanding of doctors' vulnerability to life and career vicissitudes. ${ }^{1}$ More generally it highlights the fact that although there is a relatively high level of psychopathology in the profession, this is not reflected in doctors' use of psychotherapy for themselves.

Doctors seem to have difficulty acknowledging that they are vulnerable, like everyone else, to psychological distress and would benefit from the psychotherapy they prescribe for others. Equally, their colleagues seem unsympathetic to their need for psychotherapy. It remains shameful to be depressed, anxious, or not coping with pressures. 
I recently had a rare referral (for an NHS consultation) of a doctor. He had had two serious breakdowns and was still receiving treatment from a consultant psychiatrist. In our handful of meetings he often spoke of the difficulties his mental health caused with colleagues, particularly senior colleagues, and the threat it presented to his career.

During his training no allowance had been made for his psychological vulnerability. Tiredness meant that he was less able to function well. The occasional allowance for his need not to be on call was, he felt, an impossibility. He either carried on and completed the same duties as his colleagues, knowing he was risking a further breakdown, or he gave up his career.

When I saw him his duties meant that appointments with me could be arranged when he was on duty. Despite requestsapparently agreed to-not to be on call at the time of our appointments he was repeatedly unable to attend because he was on call. Colleagues made it clear that appointments for psychological treatment were frowned on. He was forced to conclude that it was acceptable to be an alcoholic doctor but not one who recognised that he was psychologically vulnerable and sought help to overcome his difficulties.

It may be considered that my patient's problems in attending sessions are in his own mind and that he is blaming his colleagues for his own reluctance to attend. Doctors tend to be more resistant than other patients, and my patient was no exception. I think, though, that he would have attended if he had been supported by his colleagues. I also believed his report that he had been a good student academically and that his clinical work was satisfactory, although a breakdown had meant that one post had been unfinished. When I saw him he was functioning well.

Doctors should be setting an example in having treatment for psychological problems and not stigmatising anyone showing emotional vulnerability, particularly if they seek help.

G N Bolsover chartered clinical psychologist Psychology Services, Hull and East Riding Community NHS Trust, Hull HU2 8TD

NkBolsover@aol.com

1 Clark S. Why do people become doctors and what can go wrong? [Career focus.] BMJ 2000;320(classified section 15 Apr):2-3. bmj.com/cgi/content/full/320/ 7241/52-7241

\section{Assessing aggression in psychiatric inpatients}

\section{Assessing aggression can be risky}

EDITOR-Carrying out a risk assessment can be risky. Doctors should ask patients if they are carrying weapons only if they can safely cope with the immediate production of a weapon. Doctors must consider their own safety and that of the patient, relatives, and colleagues. Sanders et al recommended inquiry into the full range of aggressive ideation but issued no warning about how dangerous this can be. ${ }^{1}$ They found that one in 20 patients admitted to a psychiatric hospital in Middlesbrough regularly carried weapons. Some patients will produce their weapon on inquiry, and a few may be prepared to use it.

I have been treated to demonstrations of knives, scissors, a machete, and a (replica) gun. In most cases I had arranged for others to be present before asking about weapons, and the situations were managed safely. Not all my colleagues have been so fortunate. The staff of psychiatric wards usually have training and experience in the management of violence. They can also respond quickly to an emergency involving a weapon on the ward. Doctors and nurses who see patients at home or in clinics rarely have such support available unless they have made specific arrangements in advance. It is therefore advisable to organise support before asking about weapons. This support could be a visit with a colleague, or a safer venue such as the ward in preference to a clinic. With good back up and an understanding of the patient's mental state, a handover of most weapons can be instigated with minimal risk to all concerned.

The method employed by Sanders et al compared a semistructured interview about risks with case note records of aggressive ideation. It is not clear if these were medical, nursing, or multidisciplinary records. A similar study in a psychiatric hospital by Harwood and Yeomans showed that a risk interview found more evidence of risk of violence than either medical or nursing records alone. ${ }^{2}$ If the medical and nursing records were combined, however, the level of routine risk recording was better and approached the quality of the systematic interview. This paper also found that risk assessments were carried out more frequently when there was a regularly reviewed standard for risk assessment audits in place and an effective audit system to back it up.

David Yeomans consultant psychiatrist Overthorpe House, Leeds LS16 5AB d.yeomans@virgin.net

1 Sanders J, Milne S, Brown P, Bell AJ. Assessment of aggresand case note survey. BMJ 2000:320:1112. (22 April) 2 Harwood P, Yeomans D. Risk assessment. Psychiatr Bull 1998;22:446-9.

\section{Study should have been controlled}

EdiTor-Sanders et al state that most violence is carried out by mentally well people. ${ }^{1}$ They then describe an uncontrolled study, in which they report the result of nonrandomised interviews of patients admitted to a general psychiatric unit. They report seemingly high rates of violent thoughts, previous offending, and weapon ownership with no reference to a control group or baseline levels in the unit's catchment area.

In the absence of a control group matched for age, sex, social deprivation, and other important non-psychiatric risk factors with regard to violence, the results are at best meaningless and at worst highly stigmatising of psychiatric patients. Many mentally well people have violent thoughts, most own a weapon, and many will have carried a weapon. It is well recognised that psychiatric variables have little bearing with regard to risk of violence. In fact, a diagnosis of a psychotic illness can be seen as a protective factor with regard to repeat offending. ${ }^{2}$ This work may seem harmless, but poorly constructed and uncontrolled research such as this only helps to further the inaccurate stigmatisation of mentally ill people as potential killers, despite the lack of any evidence base to support this.

Sanders et al conclude that it is important for doctors to inquire systematically about the full range of aggressive ideation in patients admitted to psychiatric hospitals. Their paper provides no evidence as to why such patients should be asked any more than members of the general public. Making such a statement inaccurately implies a general increase in dangerousness associated with a psychiatric label. Had they used evening attendees at a local accident and emergency unit as controls, the "spin" of their article would have been quite different.

John J Sandford specialist registrar in forensic psychiatry

Devon and Cornwall Forensic Psychiatric Service, Langdon Hospital, Dawlish, Devon EX7 0NR john.sandford@edchs-tr.swest.nhs.uk

1 Sanders J, Milne S, Brown P, Bell A. Assessment of aggression in psychiatric admissions: a semistructured intervie and case note study. BMJ 2000;320:1112. (22 April.)

2 Bonta J, Law M, Hanson K. The prediction of criminal and violent recidivism among mentally disordered offenders: a meta-analysis. Psychol Bull 1998;123:125-43.

\section{In China, suicide in young women is a problem too}

EdiToR-Mayor reports that the Men's Health Forum recommends that suicide in young British men needs multiagency solutions rather than efforts by psychiatrists or general practitioners alone. ${ }^{1}$ This is true in China too, except that it is young women who should be the target of interventions.

China's national suicide rate has been estimated to be about 30/100 000 annually, ${ }^{2}$ about three times the global average. Consequently, China accounts for more than four tenths of suicides reported worldwide, including more than half of suicides among women (although reliable data on suicide from Central and South America, Africa, the Middle East, and huge Asian countries such as India and Indonesia are still lacking). Among women, completed and attempted suicide is a greater source of lost working days than diabetes, heart disease, or cancer.

The rate is astonishingly high in young rural women aged 15-24, which casts doubt on the view of experts such as Baechler that "women endure misfortune better than do men. Their social roles require them to face unbearable problems less frequently.... As daughters, wives, and mistresses, and conforming to the dependency which nature and culture encourage, women have a greater tendency to reach their ends by the threat of trying to kill themselves.... 
Dangerous and aggressive behavior generally is not characteristic of women."3

Evidence suggests that high rates of suicide in young Chinese rural women have multiple causes: low social status, forced marriage, domestic abuse, birth control policy, harassment by the husband's family, frustration over rural life, easy availability of pesticides, and greatly limited access to medical resuscitation facilities. ${ }^{4}$ Since most rural Chinese people do not have medical insurance and psychiatrists and even general practitioners are barely available in many rural areas, the prevention of suicide must rest, provided political will is available, on the intersectoral collaboration of multiple local agencies.

Sing Lee senior lecturer in psychiatry

Chinese University of Hong Kong, Prince of Wales Hospital, Shatin, Hong Kong

singlee@cuhk.edu.hk

1 Mayor S. Suicide in young men needs multiagency solutions [news extra] bmj.com/cgi/content/full/320/ $7242 / 1096 / d$

2 Phillips M, Liu HQ, Zhang YP. Suicide and social change in Phillips M, Liu HQ, Zhang YP. Suicide and soci
China. Culture Med Psychiatry 1999;23:25-50.

China. Culture Med Psychiatry 1999;23:25-50.

4 Lee S, Kleinman A. Suicide as resistance in Chinese Lee S, Kleinman A. Suicide as resistance in Chinese
society. In: Perry EJ, Selden M, eds. Chinese society: change, conflict and resistance. London: Routledge, 2000:221-40.

\section{Optimal age for starting lipid lowering treatment}

\section{A 10 year risk of $30 \%$ should be used}

EDITOR-Ulrich et al have bravely attempted to tackle a problem that has been quietly sidestepped for some time-namely, that lipid lowering does not (as far as we are aware) prevent coronary heart disease, it merely postpones it. ${ }^{1}$ The concept of assessing treatment in terms of "event free life years gained" is a useful one, but using a risk calculator to estimate potential benefit is fraught with difficulty.

The authors base their calculation on the Framingham equation, in common with most coronary risk calculators, and have made one particularly common but incorrect assumption regarding age. With the publication of the Framingham equation, Anderson et al stated that the equation "may be used for estimating outcome probabilities over a range of 4 to 12 years for persons aged 30 to 74 years."' Quoting calculated risks for ages 15 to 94 is therefore inappropriate. To attempt to recalculate such risks using a pharmacologically lowered cholesterol concentration is even less appropriate.

Anderson's statement is also relevant to the notion of a " $3 \%$ annual risk," which cannot be reliably predicted by the Framingham equation directly. The joint British guidelines circumvent this by referring to a "30\% 10 year risk," which will in fact identify subjects whose initial risk is less than 3\% per year because the risk is higher in the later years. ${ }^{3}$

Finally, it should be remembered that the Framingham equation is less reliable at the extremes of any of the variables included; hence a very high cholesterol concentration in a young person should stimulate further clinical thought. Ulrich et al calculated the benefits of treatment for cholesterol concentrations of $9 \mathrm{mmol} / \mathrm{l}$ and higher. People with these concentrations require proper investigation of their dyslipidaemia rather than a keyboard exercise to estimate (badly) cardiovascular risk.

William G Simpson consultant in clinical biochemistry

Aberdeen Royal Infirmary, Foresterhill, Aberdeen AB25 2ZD

W.G.Simpson@arh.grampian.scot.nhs.uk

Patrick Twomey specialist registrar in clinical

biochemistry

Edinburgh Royal Infirmary, Edinburgh EH3 9YW

Competing interests: None declared.

1 Ulrich S, Hingorani AD, Martin J, Vallance P. What is the optimal age for starting lipid lowering treatment? A mathematical model. BMJ 2000;320:1 134-40. (22 April.)

2 Anderson KM, Odell PM, Wilson PWF, Kannel WB Cardiovascular disease risk profiles. Am Heart J 1991;121: 293-8

Wood D, Durrington P, Poulter N, McInnes G, Rees A,

Wray R. Joint British guidelines on prevention of coronary Wray R. Joint British guidelines on prevention of coronary
heart disease in clinical practice. Heart 1998:80(suppl 2): S1-29.

\section{It is more efficient to screen and treat elderly people}

EDITOR-Ulrich et al indicate that starting statin treatment at the age of 40 is the most efficient treatment strategy. ${ }^{1}$ Intuition suggests that prevention should be most efficient in patients at highest risk. Why the difference? Could their model be misleading?

For reasons of simplicity, their paper uses "event free life years" as an outcome measure. Preventing a cardiovascular event in a 30 year old man and a man of 70 gains, respectively, 28.7 and 1.8 event free life years. This measure therefore weights a cardiovascular event in a young man as 16 times more important than one in an older man. The authors' value judgment is not immediately apparent to readers.

An estimate of "life years lost" after a cardiovascular event is shown in the table. Mortality after myocardial infarction is a proxy for mortality after a cardiovascular event. Preventing a myocardial infarction in a 30 year old man and a 70 year old man saves, respectively, 10.6 and 6.6 years of life. Because not all cardiovascular events are myocardial infarctions this overestimates the life years lost. Nevertheless, mortality is clearly lower in younger patients.

Efficiency of starting treatment with statin at different ages in men

\begin{tabular}{lcccccc} 
Age & $\begin{array}{c}\text { Event free life } \\
\text { years expected }\end{array}$ & $\begin{array}{c}\text { Life expectancy } \\
\text { (years) }\end{array}$ & $\begin{array}{c}\text { Case fatality } \\
\text { rate* }(\%)\end{array}$ & $\begin{array}{c}\text { Life years lost after } \\
\text { cardiovascular } \\
\text { event }\end{array}$ & $\begin{array}{c}\text { Life years } \\
\text { gained by } \\
\text { treatmentt }\end{array}$ & $\begin{array}{c}\text { Life years gained } \\
\text { per year of } \\
\text { treatment }\end{array}$ \\
\hline 20 & 38.4 & 55.5 & 23 & 12.8 & 3.8 & 0.06 \\
\hline 30 & 28.7 & 45.9 & 23 & 10.6 & 3.2 & 0.06 \\
\hline 40 & 19.5 & 36.5 & 23 & 8.4 & 2.5 & 0.06 \\
\hline 50 & 11.6 & 27.1 & 29 & 7.9 & 2.4 & 0.08 \\
\hline 60 & 5.5 & 18.7 & 46 & 8.6 & 2.6 & 0.12 \\
\hline 70 & 1.8 & 11.7 & 56 & 6.6 & 2.0 & 0.14 \\
\hline 80 & 0.3 & 6.7 & 56 & 3.8 & 1.1 & 0.14 \\
\hline
\end{tabular}

*Mortality after myocardial infarction is used as a proxy for mortality after a cardiovascular event.

tRelative risk reduction adjusted to $30 \%$ at all ages.
Ulrich et al used the Framingham risk equation to predict the relative reduction of risk with treatment. Effectiveness seems to decrease with age- - for example, treatment at age 70 reduces risk by only $14 \%$. However, this equation was intended to predict risk, not effectiveness of treatment. The evidence on effectiveness indicates that the relative reduction of risk is $32 \%$ in people over 65 and that there is no relation between age and relative reduction of risk. ${ }^{3}$

If the relative reduction of risk with treatment is adjusted to $30 \%$ at all ages and the outcome expressed in life years gained per year of treatment, a very different conclusion is reached: it is most efficient to treat the oldest patients (table). This holds true as mortality after a cardiovascular event is higher in older patients.

Finally, because Ulrich et al's paper is concerned only with treatment, it does not consider which patients clinicians should assess. The efficiency of identifying and then treating patients is quite different from the efficiency of treatment alone. Ulrich et al made no estimation of the effect on workload of identifying patients. In screening for cardiovascular risk factors, it is more efficient to look for patients among elderly people, in whom the prevalence of coronary heart disease is high.

Tom Marshall lecturer in public health medicine Department of Public Health and Epidemiology, University of Birmingham, Birmingham B15 2TT

Competing interests: None declared.

1 Ulrich S, Hingorani AD, Martin J, Vallance P. What is the optimal age for starting lipid lowering treatment? A mathematical model. BMJ 2000;320:1 134-40. (22 April.)

2 Norris RM on behalf of the United Kingdom Heart Attack Study Collaborative Group. Fatality outside hospital from acute coronary events in three British health districts, 1994-5. BMJ 1998:316:1065-70.

3 LaRosa J, He J, Vupputuri S. Effect of statins on risk of coronary disease. A meta-analysis of randomized controlled trials. JAMA 1999;24:2340-6.

\section{Adjusted data do not justify a lower optimal age}

EDITOR-Ulrich et al propose a modification of risk assessment of statin treatment for coronary heart disease that aims to offset the overweening effect of age on absolute risk. ${ }^{1}$ The concept is important but very complex-perhaps too complex for many readers. The crux of the proposal is in figure 3(c) of their paper, which seems to show that men at moderately high risk of coronary heart disease get maximal gain in "event free 

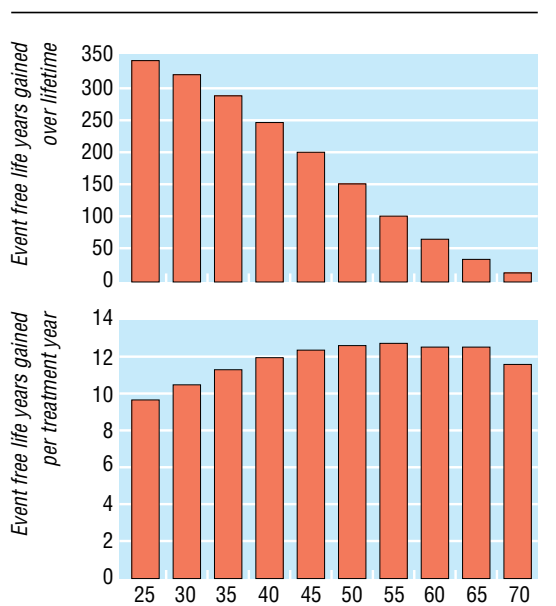

Age treatment started (years)

Top: Total number of event free life years gained at different ages of starting treatment. Bottom: Number of life years gained that were free of events per year of treatment at different ages of starting treatment

years of life" for each year of statin treatment when treatment is started at the age of 40 , the "optimal" age. This means starting statin treatment some 20 years earlier than would be the case according to current policy, as shown in their figure $3(\mathrm{a})$.

The calculations that underpin these two figures are shown in the table in Appendix 1 of their paper. We believe that this life table is seriously inaccurate, largely because of rounding and other errors in the row entitled " 5 year absolute risk of coronary heart disease (\%)" and because the years of statin treatment are calculated incorrectly. Using the difference between 75 years and the age at which treatment is started as the duration of statin use implies that some people continue to take treatment after death. The only benefits considered in the analysis are those of primary prevention, and the duration of treatment used in the calculations should logically be the time from starting treatment until death from causes other than coronary heart disease or until the first cardiovascular event. When the data in the table are corrected for these errors the authors' conclusions are no longer justified.

We have recalculated the life table and produced revised versions, derived from the modified calculations, of Ulrich et al's figures 3(a) and 3(c) (figure (top) and (bottom), respectively). The top part of the figure shows a simple monotonic decline in total life years gained as the age of starting treatment increases, a finding reported by Grover et al. ${ }^{2}$ The recast figure for life years gained free of coronary heart disease per year of statin treatment (figure (bottom)) shows very little difference when statin treatment is started at different ages in the range 45-65 years, with the "optimal" age now about 55 years. This is close to the age (60) that confers an absolute risk of $30 \%$ over 10 years and at which current guidelines recommend starting statin treatment. There is no important difference between targeting statin treatment at this new threshold and targeting it at a risk threshold based on absolute risk of coronary heart disease, and the added complexity is certainly not justified.

Peter R Jackson reader of clinical pharmacology and therapeutics

Peter.R.Jackson@sheffield.ac.uk

Erica J Wallis research assistant

Lawrence E Ramsay professor of clinical

pharmacology and therapeutics

Section of Clinical Pharmacology and

Therapeutics, Division of Clinical Sciences (CSUH

Trust), Royal Hallamshire Hospital, Sheffield

S10 2JF

Competing interests: PRJ and LER have received fees for speaking, research funds, or assistance in attending conferences from BMS, MSD, Novartis, Parke-Davis, and Pfizer.

1 Ulrich S, Hingorani AD, Martin J, Vallance P. What is the S ematical model. BMJ 2000;320:1134-40. (22 April.)

2 Grover SA, Abrahamowicz M, Joseph L, Brewer C, Coupa L, Suissa S. The benefits of treating hyperlipidaemia to prevent coronary heart disease. Changes in life expectancy prevent coronary heart disease. Chang
and morbidity. JAMA 1992;267:816-22.

\section{Authors' reply}

EDITOR-We are pleased our article has helped to broaden the debate on the optimal age for starting lipid lowering treatment. We agree with Simpson and Twomey about the age range used in the Framingham equation, but other publications suggest that the equation also predicts lifetime risk. ${ }^{12}$ We disagree about the problems in calculating therapeutic effects-lowering cholesterol reduces risk in line with the lowering. ${ }^{3}$ They are right to suggest that a cholesterol concentration of $9 \mathrm{mmol} / 1$ requires investigation, but we think that both investigation and risk prediction are required, not just the former.

Marshall writes: "In screening for cardiovascular risk factors, it is more efficient to look for patients among elderly people." What is the evidence base for this firm conclusion? If the target is to avoid (or delay) cardiovascular events over a short time then the statement is true. But if the aim is to produce healthier individuals in middle and old age, this may not be the appropriate therapeutic approach. ${ }^{4}$ We modelled the effects of different approaches and avoided value judgments. It seems eccentric to conclude that because treatment adds 28.7 healthy years to a young cohort and 1.8 to an older one we rate the avoidance of a cardiovascular event as 16 times more important in the young. Finally, we did not say that the optimal age for treatment is 40. Rather, we said that an optimal age can be calculated, and for this example it happened to be 40 .

We are pleased that Jackson et al accept the concept of an optimal age to start treatment. Our aim was to present the complex data underpinning the concept; clearly, any clinical tool would need to provide a simple readout. Jackson et al challenge certain of our calculations. In calculating optimal age for treatment we excluded individuals who had died or who had had an event, so our figure 3(a) stands. They were right to question the years of statin treatment and we are grateful for the correction, but when we adjust for this we find that the graph shape remains similar, the absolute benefit per treatment year is even higher, and the optimal age for treatment remains at 40 . Jackson et al should be careful when concluding that the age at which maximum gain per year of treatment is achieved and the age that confers a 30\% 10 year absolute risk threshold is always the same-it isn't. Our question is which system should be used to arrive at a treatment start age when, other things being equal, the two calculations give different answers. Implicit in their letter is an acceptence of the method we propose.

Patrick Vallance professor patrick.vallance@ucl.ac.uk

Aroon D Hingorani British Heart Foundation Gerry Turner fellow

Silvia Ulrich visiting research fellow

Centre for Clinical Pharmacology and

Therapeutics, University College London, London WC1E 6JJ

1 Lloyd-Jones DM, Larson MG, Beiser A, Levy D. Lifetime risk of coronary heart disease. Lancet 1999:353:89-92.

2 Ulrich S, Hingorani AD, Martin H, Vallance P. Lifetime risk of developing coronary heart disease in the UK. Lancet 1999;353:925

3 Law MR, Wald NJ, Thompson SG. By how much and how quickly does reduction in serum cholesterol concentration lower risk of ischaemic heart disease? BMJ 1994;308 $367-72$.

4 Albert D. Risk in cardiovascular disease. $B M J$ 2000;321:175

\section{Anticoagulation for patients with atrial fibrillation}

\section{Editorial may have overinterpreted data}

Editor-Connolly's view that Kalra et al's findings clearly show that the results of anticoagulation studies can be replicated in general medical practice may be an overinterpretation of the data. ${ }^{12}$ The 167 patients in the study may not have been a representative sample of high risk patients found in general practice. Patients were recruited from secondary care medical clinics, not general practice, and bias in the study group could have been introduced by selection for hospital referral. Furthermore, bias could have occurred by exclusion of those high risk patients who were already taking warfarin, who may have been considered by their general practitioner to have been at a lower risk of haemorrrhagic complications or a greater risk of stroke. Knowledge of the outcome of the 76 patients already taking warfarin, who presumably were being managed by the same anticoagulation service as trial patients, is also required.

The most striking finding from Kalra et al's study was that 167 of $172(97 \%)$ high risk patients agreed to warfarin treatment. Knowledge of how this level of acceptance was achieved would be useful for clinical practice. Howitt and Armstrong found that after patients in general practice were educated about stroke, given detailed information about aspirin and warfarin, and shown a pictorial representation of risk and expected benefits of treatment only 10 of 56 patients started warfarin, 20 declined treat- 
ment, one changed from warfarin to aspirin, and the remainder continued to take warfarin. ${ }^{3}$ In contrast, Sudlow et al found that $78 \%$ of women and $93 \%$ of men aged 75 and over, the majority of whom were at high risk, would take a tablet (warfarin) to prevent stroke, but patients were only told the overall benefits of treatment and not told specifically about risks. ${ }^{4}$ Acceptance of treatment declined if anticoagulation monitoring was carried out at the hospital or general practitioner's surgery. The same group has also highlighted the factors influencing general practitioners' use of warfarin and did not find that warfarin was considered too expensive to manage in primary care and willingness to use it could be encouraged by further remuneration.

Maybe it is not crucial to educate doctors about the benefits of warfarin, but perhaps the key to increasing its use in high risk patients is to adopt Kalra et al's approach to discussing "warfarinisation," whatever that is, deliver the monitoring service in the patient's home, and remunerate general practitioners adequately for supervising the treatment and screening patients to identify those who would be eligible for treatment.

Nigel Dudley consultant in general/elderly medicine Pinderfields Hospital, Wakefield WF1 4DG nigel.dudley@panp-tr.northy.nhs.uk

1 Connolly S. Anticoagulation for patients with atrial fibrillation and risk factors for stroke. BMJ 2000;320:121920. (6 May.)

2 Kalra L, Yu G, Perez I, Lakhani A, Donaldson N. Prospective cohort study to determine if trial efficacy of anticoagulation for stroke prevention in atrial fibrillation translate into clinical effectiveness. BMJ 2000;320:1236-9. (6 May.)

3 Howitt A, Armstrong D. Implementing evidence based medicine in general practice: audit and qualitative study of antithrombotic treatment for atrial fibrillation $B M J$ 1999;318:1324-7.

4 Sudlow M, Thomson R, Kenney R, Rodgers H. A community survey of patients with atrial fibrillation: associated disabilities and treatment preferences. Br J Gen Pract 1998;48:1775-8.

5 Rodgers H, Sudlow M, Dobson R, Kenney R, Thomson R. Warfarin anticoagulation in primary care: a regional Warfarin anticoagulation in primary care: a regional
survey of present practice and clinicians' views. Br J Gen Survey of present prac
Pract 1997:47:309-10.

\section{Warfarin should be given for up to one year after successful cardioversion}

EDITOR-The editorial by Connolly draws attention to the failure of doctors to prescribe warfarin for patients with atrial fibrillation. ${ }^{1}$ This fact is substantiated by a considerable amount of evidence. We wish to highlight one further, unrecognised, reason why some patients with atrial fibrillation may not receive anticoagulation treatment.

Cardioversion of atrial fibrillation is commonly attempted, but with optimal results obtained only in those patients with recent onset atrial fibrillation who are young, are normotensive, and have structurally normal hearts. We have recently completed a prospective observational study of elective electrical cardioversions performed in 111 consecutive patients over a 12 month period in our hospital, a tertiary referral university centre. Sinus rhythm was restored immediately in 96 out of $111(86 \%)$ patients. Only 54 out of $88(61 \%)$ patients in sinus rhythm at discharge remained in this rhythm at one month. Of these 54, a further $21(39 \%)$ had relapsed into atrial fibrillation by 12 months.
Independent predictors of sinus rhythm at discharge were younger age (odds ratio 1.11; $95 \%$ confidence interval 1.04 to 1.16 $\mathrm{P}=0.002)$ and absence of hypertension (1.73; 1.22 to $1.91 ; \mathrm{P}=0.015)$. The presence of sinus rhythm at discharge $(6.4 ; 1.6$ to 25.3 ; $\mathrm{P}=0.007)$ was an independent predictor of sinus rhythm at one month, whereas age was a negative predictor $(0.96 ; 0.92$ to 1.0 ; $\mathrm{P}=0.05$ ). The presence of sinus rhythm at one month was the only predictor of sinus rhythm at one year $(4.8 ; 2$ to $11.1 ; \mathrm{P}=0.002)$. In this study, although electrical cardioversion for atrial fibrillation had a high initial success rate, only a minority of patients remained in sinus rhythm at one year.

This observation is paralleled by similar findings in other comparable studies..$^{2-5}$ The common practice of discontinuing anticoagulant treatment in patients in sinus rhythm at the clinic review one month after discharge will therefore lead to an increased risk of thromboembolism in many patients with undiagnosed recurrent atrial fibrillation one month after discharge. Given these findings, we believe that warfarin should be given for up to one year in patients in whom cardioversion has been successful. Further data are required to establish which patients, if any, may safely discontinue anticoagulation treatment at the time of clinic review.

Colin Berry Medical Research Council clinical training fellow

Department of Cardiology, Western Infirmary, West Glasgow Hospitals University Trust, Glasgow G11 6NT

colin.berry@clinmed.gla.ac.uk

John McMurray professor of medical cardiology Clinical Research Initiative in Heart Failure, University of Glasgow, Glasgow G12 8QQ

1 Connolly S. Anticoagulation for patients with atrial fibrillation and risk factors for stroke. BMJ 2000;320:121920. (6 Mav.)

2 Sudlow M, Thomson R, Thwaites B, Rodgers H, Kenny RA

Prevalence of atrial fibrillation and eligibility for antiPrevalence of atrial fibrillation and eligibility for ant-
coagulation in the community. Lancet 1998;352:1167-71. 3 Clinical Quality Improvement Network. Thromboembolic 3 Clinical Quality Improvement Network. Thromboembolic prophylaxis in 3575 hospitalized patient
lation. Can J Cardiol 1998;14:695-702.

4 Van Gelder IC, Crijns HJ, Van Gilst WH, Verwer R, Lie KI Prediction of uneventful cardioversion and maintenance of sinus rhythm from direct current electrical cardioversion of chronic atrial fibrillation and flutter. Am J Cardio 1991;68:41-6

5 Crijns HJ, Van Gelder IC, Van Gilst WH, Hillege H, Gosselink AM, Lie KI Serial antiarrhythmic drug treatment to maintain sinus rhythm after electrical cardioversion for chronic atrial fibrillation or flutter. Am J Cardio 1991:68:335-41.

\section{Action on Cataracts should influence surgical training}

EDITOR-The management of cataract is one of the spectacular surgical success stories of recent years. Day care is now the norm, and visual rehabilitation is rapid and dramatic. As a result, the uniformly excellent outcome of this technically highly complex eye operation is now almost taken for granted.

In 1998-9 some 170000 cataract operations were performed in the NHS. But Action on Cataracts, launched by the NHS Executive earlier this year, ${ }^{1}$ draws attention to the patchiness of services and the long delays experienced by many patients. It presses for the better organisation of services, and the need for them to be patient focused. Many of these recommendations are innovative and exciting, and the NHS Executive anticipates that this initiative will result in a $47 \%$ increase in cataract operations, to 250000 annually, by 2003.

Pressure on trusts will increase, especially in those areas that are identified as poor performers. ${ }^{1}$ This is likely to further damage surgical training, which is already crumbling under the strain. A recent survey reported that $30-40 \%$ of senior house officers in the United Kingdom have not performed an operation in the past month and fewer than $30 \%$ achieve the minimum number required to enter higher surgical training. ${ }^{2}$ This means that senior house officers are not being exposed to adequate surgical training-an extraordinary indictment of our surgical training. This unsatisfactory situation can only be deepened by Action on Cataracts, which contains not one mention of training for any member of the ophthalmic team, let alone for the burgeoning surgeon.

This is a serious predicament and requires urgent resolution. On the one hand, the amount of cataract surgery needs to increase by $47 \%$ in three years and to be sustained at this level. On the other hand, the training of our young surgeons is inadequate. Action on Cataracts presents an excellent opportunity for the NHS Executive to improve ophthalmic services.

This document makes several excellent suggestions for the service but not for training, so here are a few ideas. High volume service and low volume training surgical lists should be created. Attention must also be given to both surgical numbers and the rate at which they are achieved by the trainee, as experience gained from performing one operation infrequently is far less effective than blocks of intensive training, which also minimises the surgical learning curve. If the NHS Executive were to admit to the conflict between service and training we might formally address the issue and get surgical training sorted out at last.

Alistair R Fielder professor of ophthalmology a.fielder@ic.ac.uk

Martin P Watson senior house officer

Academic Department of Ophthalmology, Imperial College School of Medicine, Western Eye Hospital, London, London NW1 5 YE

Helen C Seward consultant ophthalmic surgeon Mayday University Hospital, Croydon CR7 7YE

Philip I Murray professor of ophthalmology

Birmingham and Midland Eye Centre,

Birmingham B18 7QH

1 NHS Executive. Action on cataracts: good practice guidance Leeds: NHS Executive, 2000

2 Training news 2000;issue 5:1-2. (Supplement to College News. Quarterly Bulletin of the Royal College of Ophthalmologists 2000; spring.)

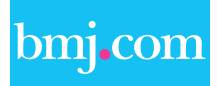

\section{Rapid responses}

Correspondence submitted electronically

is available on our website 